\title{
MONITORING OF FLOWER VISITING INSECTS ON BUCKWHEAT (FAGOPYRUM ESCULENTUM MOENCH.) IN CHITWAN, NEPAL
}

\author{
L.N. Aryal ${ }^{1 *}$, R.B. Thapa ${ }^{1}$, S. Tiwari ${ }^{2}$ and N.K. Chaudhary ${ }^{4}$ \\ ${ }^{1}$ Institute of Agriculture and Animal Science, Tribhuvan University, Nepal \\ ${ }^{2}$ Department of Entomology, Agriculture and Forestry University, Rampur, Nepal \\ *Corresponding author's email: loknatharyal44@gmail.com
}

\begin{abstract}
This paper presents the finding of the field experiment conducted on monitoring of flower visiting insects on buckwheat (Fagopyrum esculentum Moench.) at farmers' field during winter, 2012/13 at Meghauli, Chitwan, Nepal. The abundance and distribution of flower visiting insects were studied by monitoring with insect net and pan traps at $500 \mathrm{~m}, 1500 \mathrm{~m}$ and $2800 \mathrm{~m}$ from the natural habitat (forest). The wild insects (wasps and Apis dorsata F.) were found higher near to natural habitat and domesticated insects (Apis mellifera L. and Apis cerana F.) found more away from the natural habitat or close to housing and apiaries. Besides, Apis florea F., Andrena sp., Synoeca sp., Chalcid sp., Formica sp., Syrphus sp. and various Dipteran, Coleopteran, and Lepidopteran were also the flower visitors of buckwheat close to natural habitat. So, the diversity index varied with distance from the natural habitat, i.e. increase on proximity to natural habitat, i.e. $1.11,1.25$ and 1.62 at $2800 \mathrm{~m}, 1500 \mathrm{~m}$ and $500 \mathrm{~m}$, respectively on sweeping with insect net and $0.65,1.04$ and 1.30 at $2800 \mathrm{~m}, 1500 \mathrm{~m}$ and $500 \mathrm{~m}$, respectively on setting pan traps. Thus, the number and diversity of flower visiting insects get increased on proximity to natural habitat suggesting either conservation of natural habitat (forest) near farming communities or shifting of buckwheat cultivation near to natural habitat for adequate pollination and production.
\end{abstract}

Keywords: monitoring; buckwheat; pollination; insects; honeybees

\section{Introduction}

Buckwheat (Fagopyrum esculentum Moench.) is the indeterminate 'Pseudocereal' belonging to family Polygonaceae (Marshall and Pomeranz, 1982). In Nepal, it occupies 10,510 ha of land area with productivity of 0.98 t/ha (ABPSD, 2013/014). Pollination by insects is an important and necessary process on many cultivated crops including common buckwheat. Globally, about 30\% of human food resulting from about $80 \%$ of the crop pollination is from insect pollination (McGregor, 1976).

Insects foraging is determined by various plant factors as well as climatic factors such as the floral physiology and morphology, pollinator characteristics, as well as weather influence for better pollination. It is said that buckwheat pollen is not windblown so, insect pollination is required. Bee pollination increases the yield of buckwheat by $25-30 \%$ (Grigorenko, 1979) and three to four insect visits are enough to pollinate one blossom of buckwheat (Bjorkman, 1995). Seed set in buckwheat is globally low i.e. around 15-30\% which is the major constraint to buckwheat production worldwide. Insect monitoring should be done in the experimental sites only under good weather conditions: temperature $\geq 15^{\circ} \mathrm{C}$, low wind, no rain, dry vegetation and at main blooming period, that is when $\geq 10 \%$ of the plants have started to bloom (Westphal et al., 2008). The data recordings may vary depending upon the flowering phenology and type of the crop. For determinate crops with a short flowering cycle that lasts only 10 to 15 days, such as apple trees, for example, insect counts should be done every 3 to 4 days, while for indeterminate crops, such as buckwheat, it can be done on a weekly or fortnightly basis so as to cover the whole flowering season.

For insect monitoring by sweeping, the cropped area is swept up 10-12 times with the help of insect net and the sample is taken to the lab for identification. Likewise, setting of pan traps is done by putting the sweet smelling liquid in different colored pan i.e. yellow, blue or white each separated by $3 \mathrm{~m}$ distance and after 24 hours the trapped insects are taken to lab for identification.

\section{Materials and Methods}

The research was conducted during November 2012 to March 2013 in farmers' field at Meghauli-9, Dharampur, Chitwan, Nepal. The climate of the area is sub- 
tropical type. The average maximum and minimum temperatures were $30.20^{\circ} \mathrm{C}$ and $5.90^{\circ} \mathrm{C}$ in March 2013 and December 2012- January 2013, respectively. Relative humidity was the lowest in February $(91.10 \%)$ and the highest $(95.70 \%)$ in January 2013. There was no rainfall during November, December and February.

Insects found in the buckwheat field were studied both by sweeping and by setting pan traps. Sweeping with insect net was done at three different stages of buckwheat, i.e. at $10 \%$ blooming, peak blooming and $10 \%$ final to blooming stage. The sweeping were done on three successive days on each stage at three different distances from natural habitat, i.e. $500 \mathrm{~m}, 1500 \mathrm{~m}$ and $2800 \mathrm{~m}$, respectively. Also, thirty pan traps with 3 colors, i.e. yellow, blue and white, each with 10 replications arranged in alternate position spaced $3 \mathrm{~m}$ apart were used to monitor the flower visiting insects of buckwheat. The pan traps were placed for $24 \mathrm{hrs}$ in the field. This procedure was repeated for three locations from the natural habitat, i.e. $500 \mathrm{~m}, 1500 \mathrm{~m} 2800 \mathrm{~m}$, respectively. The insects trapped were taken in lab and identified.
The diversity of insect pollinators of buckwheat was calculated by using Shannon-Weaver diversity index Hs (Nolan and Callahan, 2006).

$\mathrm{H}_{\mathrm{s}}=-\sum_{i=1}^{s} p i$ Log $\mathrm{pi}$

Where $\mathrm{Hs}$ is the diversity index for insects in a group of $\mathrm{s}$ species; and pi is the relative abundance of species i. Hs does not describe evenness, i.e. dominance of certain species within insect community. The evenness index E, was calculated to describe the dominance of the prevailing insect species:

$\mathrm{E}=\frac{H s}{\ln (s)}$

Where $\mathrm{E}$ is evenness of the communities; $\mathrm{Hs}$ is the Shannon- Weaver index; $\ln$ is natural $\log$; $s$ is the number of total species. Value always lies between 0 and 1 . If the frequencies of the species do not differ significantly, E results closer to 1 and vice-versa closer to 0 .

Table 1: List of flower visiting insects in buckwheat field at Meghauli, Chitwan, Nepal, 2012/13

\begin{tabular}{|c|c|c|c|c|}
\hline S.N. & Common name & Scientific name & Family & Order \\
\hline 1. & European honeybee & Apis mellifera $\mathrm{L}$. & Apidae & Hymenoptera \\
\hline 2. & Asian honeybee & Apis cerana $\mathrm{F}$. & Apidae & Hymenoptera \\
\hline 3. & Giant honeybee & Apis dorsata $\mathrm{F}$. & Apidae & Hymenoptera \\
\hline 4. & Small bee & Apis florae $\mathrm{F}$. & Apidae & Hymenoptera \\
\hline 5. & Bees & Andrena sp. & Andrenidae & Hymenoptera \\
\hline 6. & Black wasp & Synoeca sp. & Vespidae & Hymenoptera \\
\hline 7. & Wasps* & & Vespidae & Hymenoptera \\
\hline 8. & Chalcids & Chalcid sp. & Chalcidae & Hymenoptera \\
\hline 9. & Black garden ant & Formica sp. & Formicidae & Hymenoptera \\
\hline 10. & Syrphid fly & Syrphus sp. & Syrphidae & Diptera \\
\hline 11. & Flesh fly & Musca sp. & Sarcophagidae & Diptera \\
\hline 12. & House fly & Musca sp. & Muscidae & Diptera \\
\hline 13. & Tachinid fly & Lixophaga sp. & Tachinidae & Diptera \\
\hline 14. & Aphid & Aphis sp. & Aphididae & Diptera \\
\hline 15. & March fly & Bibilio sp. & Bibionidae & Diptera \\
\hline 16. & Lady bird beetle & Coccinella sp. & Coccinellidae & Coleoptera \\
\hline 17. & Weed beetle & Agasicles sp. & Chrysomelidae & Coleoptera \\
\hline 18. & Flea beetle & Phyllotreta cruciferae $\mathrm{G}$. & Chrysomelidae & Coleoptera \\
\hline 19. & White butterfly & Pieris sp. & Pieridae & Lepidoptera \\
\hline 20. & Rice skipper & Pelopidas mathias $\mathrm{F}$. & Hesperiidae & Lepidoptera \\
\hline 21. & Tiger moths & Lophocampa ingens $\mathrm{E}$. & Gelechiidae & Lepidoptera \\
\hline 22. & Grasshopper & Hieroglyphus banian B., Oxya sp. & Acrididae & Orthoptera \\
\hline
\end{tabular}




\section{Results and Discussion}

The results of flower visiting insects during buckwheat growing season (November-2012 to March-2013) both by sweeping and setting pan traps show that most of the flower visiting insects are of Hymenoptera order, followed by Diptera, Coleoptera and Lepidoptera. The list of flower visiting insects in buckwheat field is given in Table 1.

Dhakal (2003) found that the Rock bee, Little bee, European bee, Native bee, Syrphid fly, Tabanid fly, March fly, Rice skipper, Legume pod bug, Hymenopteran wasp, Lady bird beetle, Mud wasp and Muscid fly were the flower visitors in buckwheat. Goodman et al. (2001) reported that flower visitors found in buckwheat fields were Honeybees (80.1\%), Ladybird beetle (10.10\%), Hoverflies $(2.70 \%)$, Blowflies (1.50\%), Small flies (1.50\%), Drone flies $(1.40 \%)$, Cabbage butterflies (1.30\%), Native bees $(1 \%)$, Beetles $(0.10 \%)$, Wasps $(0.10 \%)$, Moths $(0.10 \%)$ and Dragonflies $(0.10 \%)$.

\section{Distribution of Insect Pollinators on Proximity to Natural Habitat}

Monitoring were done by two ways as by sweeping with insect net and by setting pan traps to calculate the distribution of insect pollinators.

\section{By sweeping}

Sweeping were done four times in a day, i.e. i.e. at $10 \mathrm{AM}$, 12 Noon, $2 \mathrm{PM}$ and $4 \mathrm{PM}$ at three stages of the crop, i.e. at $10 \%$ blooming, peak blooming and $10 \%$ remaining to blooming stage. The average distribution of insect flower visitors of buckwheat were determined at $500 \mathrm{~m}, 1500 \mathrm{~m}$ and $2800 \mathrm{~m}$ from the natural habitat and presented in Fig. 1.

\section{By setting pan traps}

Pan traps were set at three stages of the crop, i.e. at $10 \%$ blooming, peak blooming and $10 \%$ remaining to blooming stage and average of the distribution of insect flower visitors of buckwheat were calculated at $500 \mathrm{~m}, 1500 \mathrm{~m}$ and 2800 $\mathrm{m}$ from the natural habitat. The abundance of almost all insect flower visitors was high at peak flowering stage. The results obtained are presented in Fig. 1-3.

The average insect diversity and abundance were also compared at three distances from the natural habitat and found that maximum numbers of domesticated honeybees (Apis mellifera $\mathrm{L}$. and Apis cerana $\mathrm{F}$.) at $2800 \mathrm{~m}$ from the natural habitat followed by $1500 \mathrm{~m}$ and $500 \mathrm{~m}$.

While, more number of Apis florea $\mathrm{F}$., March fly, Lady bird beetle, etc. were observed at $500 \mathrm{~m}$ from the natural habitat. Likewise, other insects were also varied with distance from the natural habitat, i.e. forest. This result is presented in Fig 5 .

Apis dorsata F. were the frequent visitors especially, at 500 $\mathrm{m}$ from the natural habitat, while Apis mellifera $\mathrm{L}$. and Apis cerana $\mathrm{F}$. were frequent away from the forest, i.e. near to housing. Observation of higher number of wasps might be due to dry land and bushy habitat near the fields. This phenomenon is described by "resource concentration" hypothesis proposed by Root (1973) to explain that insects whose requirements are fulfilled by the environment tend to remain and reproduce in that environment.

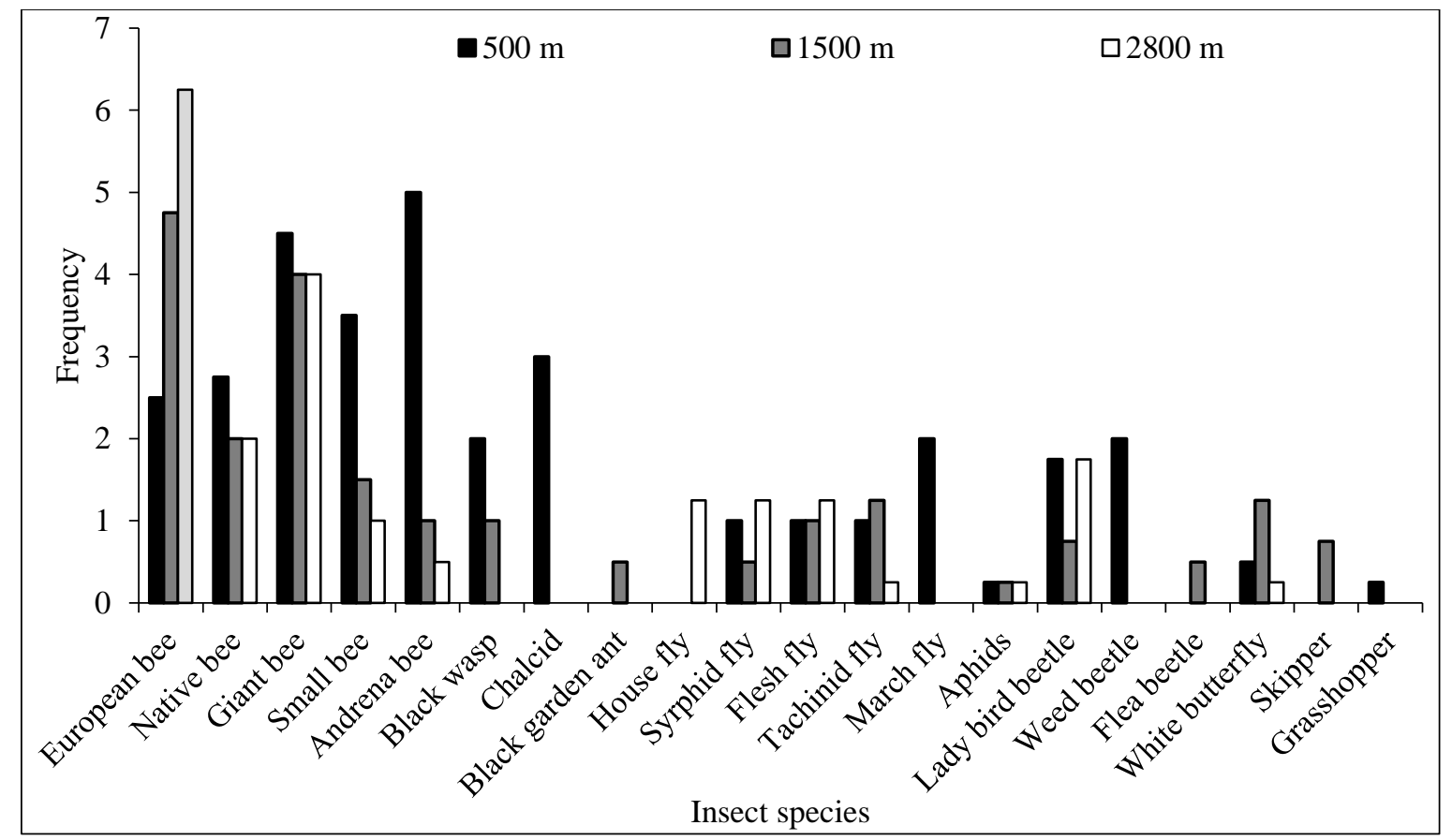

Fig. 1: Distribution of insect flower visitors of buckwheat on proximity to natural habitat (monitored by sweeping) at Meghauli, Chitwan, Nepal, 2012/13 


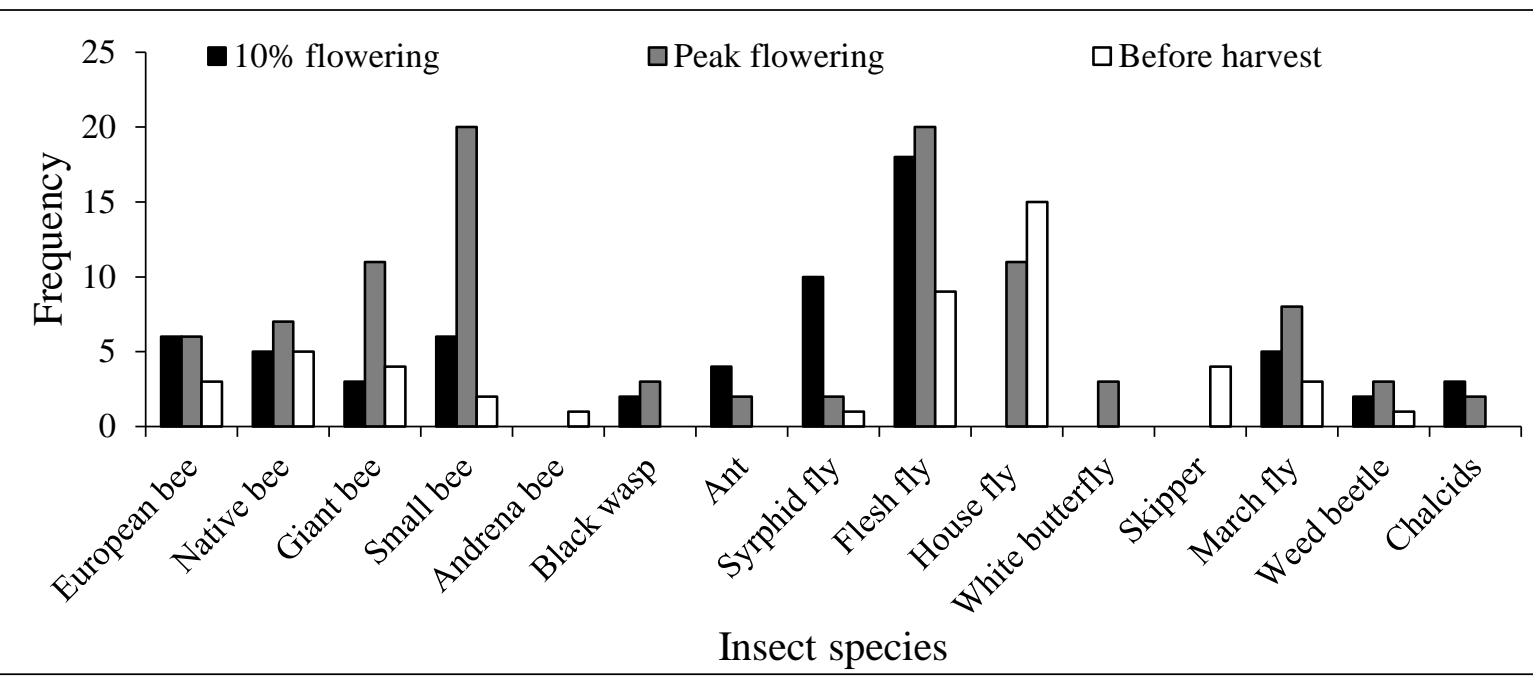

Fig. 2: Distribution of flower visiting insects of buckwheat at $500 \mathrm{~m}$ from the natural habitat at Meghauli, Chitwan, Nepal, 2012/13

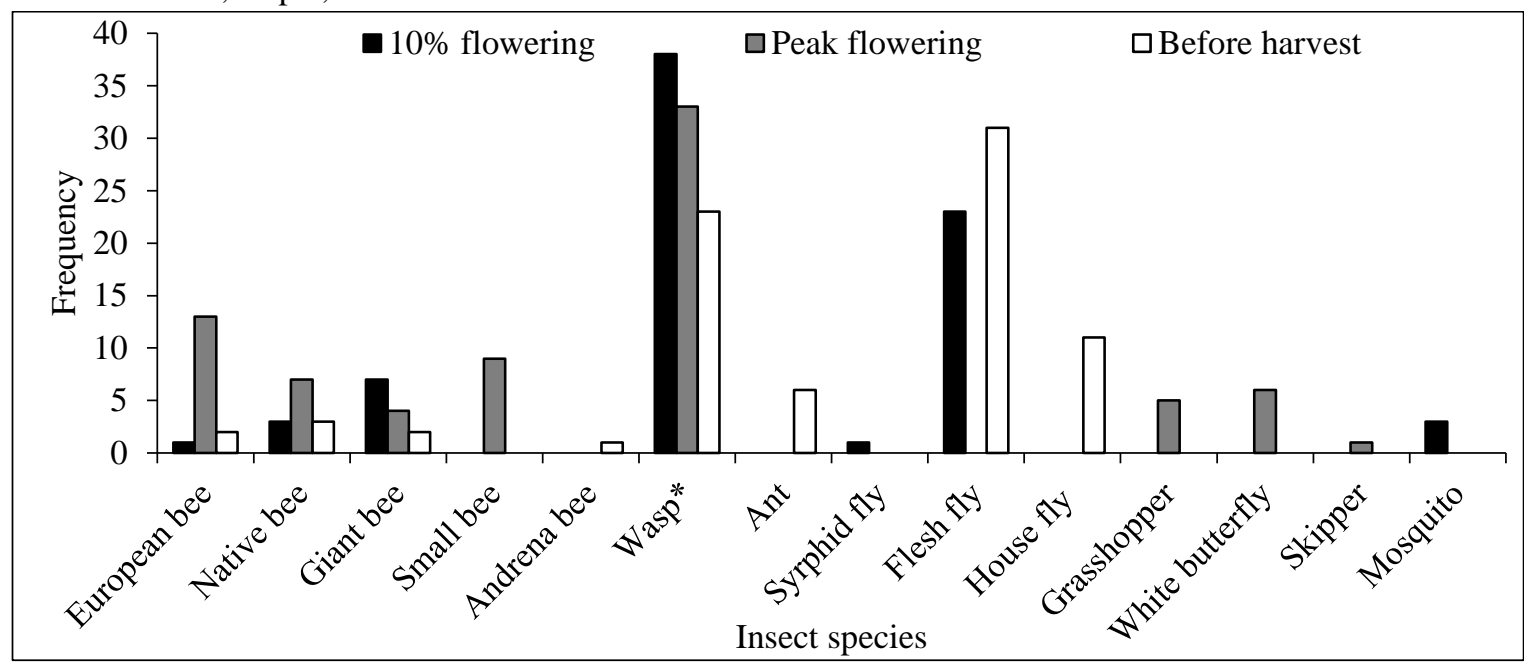

(* indicates various unidentified species of wasps)

Fig. 3: Distribution of insect flower visitors of buckwheat at $1500 \mathrm{~m}$ from the natural habitat at Meghauli, Chitwan, Nepal, 2012/13

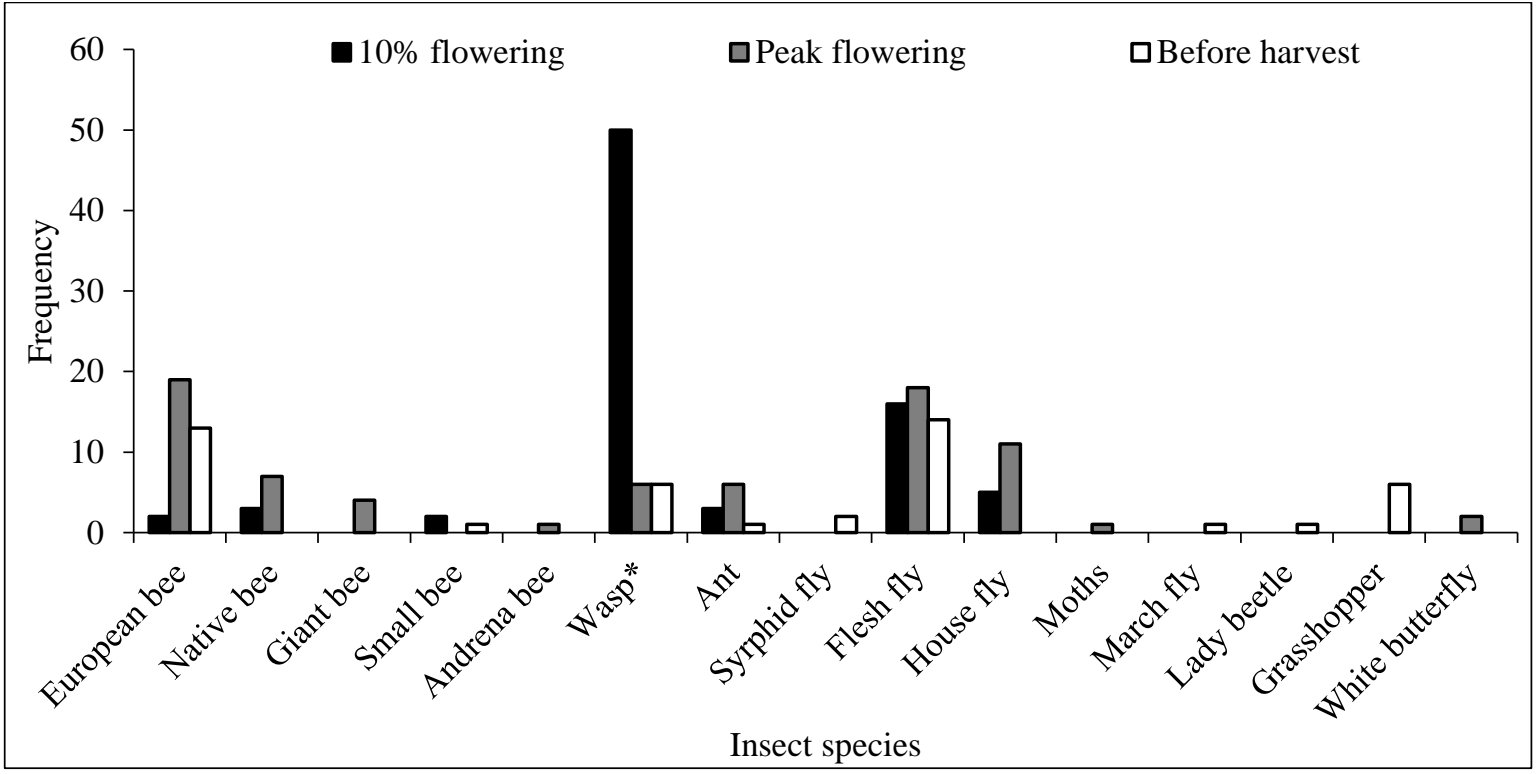

(* indicates various unidentified species of wasps)

Fig. 4: Distribution of insect flower visitors of buckwheat at $2800 \mathrm{~m}$ from the natural habitat at Meghauli, Chitwan, Nepal, 2012/13 


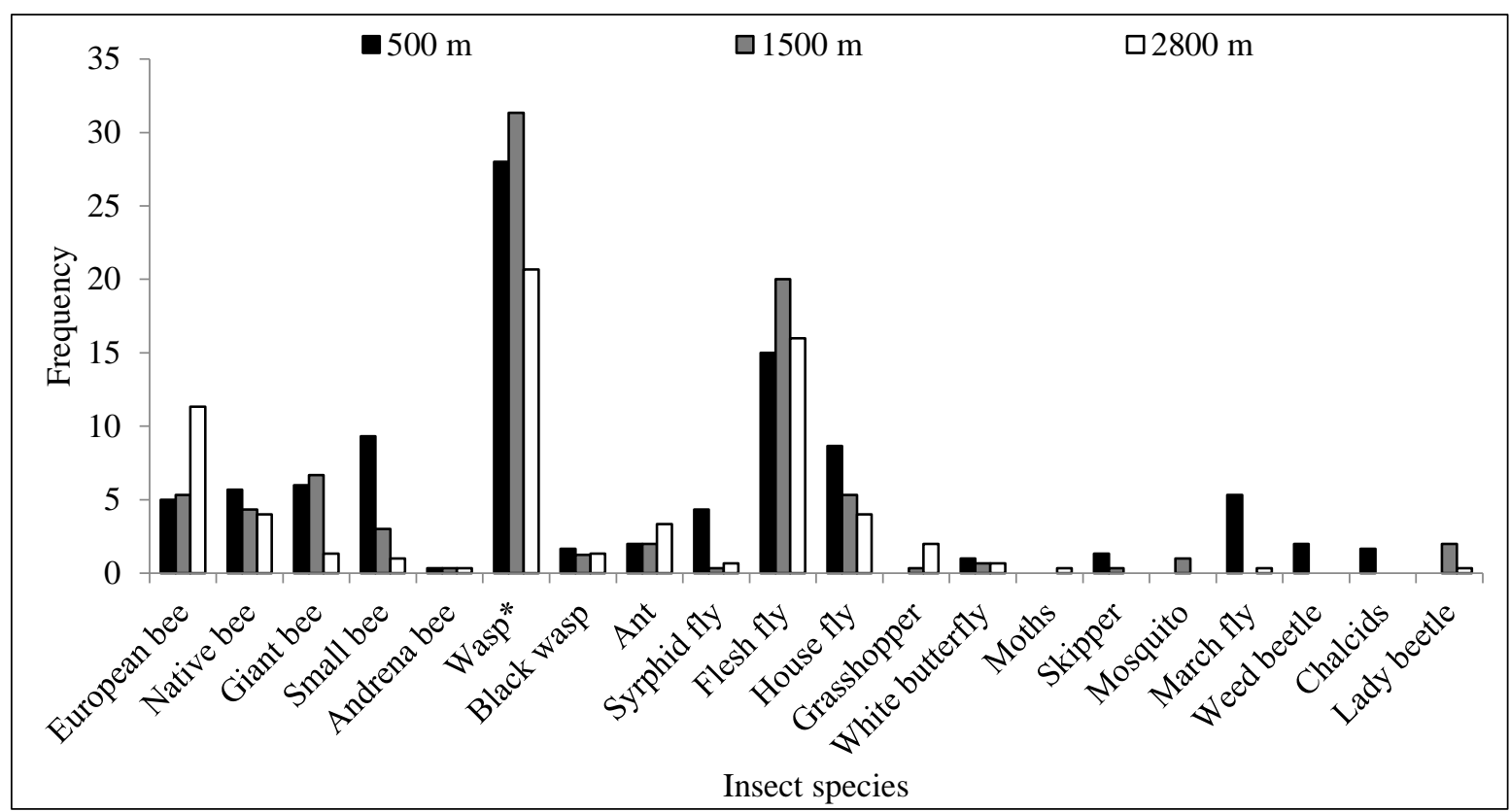

(* indicates various unidentified species of wasps)

Fig. 5: Distribution of insect visitors of buckwheat on proximity to natural habitat (monitored by setting pan traps) at Meghauli, Chitwan, Nepal, 2012/13

Table 2: Diversity measurement of insect flower visitors of buckwheat at Meghauli, Chitwan, Nepal, 2012/13

\begin{tabular}{llll}
\hline Sampling method & Distance from the natural habitat & Shannon-Weaver diversity index (Hs) & Evenness (E) \\
\hline & $500 \mathrm{~m}$ & 1.62 & 0.58 \\
Sweeping with insect net & $1500 \mathrm{~m}$ & 1.25 & 0.46 \\
& $2800 \mathrm{~m}$ & 1.11 & 0.45 \\
\hline & $500 \mathrm{~m}$ & 1.30 & 0.38 \\
By setting pan traps & $1500 \mathrm{~m}$ & 1.04 & 0.23 \\
\hline
\end{tabular}

\section{Insect Diversity and Evenness}

The Shannon- Weaver diversity index (Hs) was high at 500 $m$ from the natural habitat on both methods of insect monitoring, i.e. by sweeping and setting pan traps, followed by $1500 \mathrm{~m}$ and $2800 \mathrm{~m}$ from the natural habitat, i.e. forest. While, highest Evenness (E) was found at $500 \mathrm{~m}$ from the natural habitat, followed by $1500 \mathrm{~m}$ and $2800 \mathrm{~m}$, respectively from the natural habitat. The result obtained is presented in Table 2.

Zanette et al. (2008) showed that loss of vegetation and increased construction of buildings accounted for devastation of bee populations and hence low insect pollinator diversity. Also, pollinators vary by plant species, geographical location and time of the year (NRC, 2007: Kearns et al., 1998). The highest Evenness (E) is due to abundance of similar insect species in a particular area. The abundance and diversity of pollinators is important for the delivery of pollination services (Hoehn, 2008 and Kremen et al., 2002) which is varied with landscape context and degree of urbanization (Ahrné et al., 2009). This might be due to microclimatic variation or by habitat destruction of insects. Chacoff and Aizen (2006) and Ricketts et al. (2008) reported that wild bee populations were generally more close to natural habitat while the domesticated honeybee populations were greater near to housing and apiaries.

\section{Conclusions}

Wild insect populations such as wasps and Apis dorsata F. were the frequent visitors near to the natural habitat, while domesticated insects such as Apis mellifera L. and Apis cerana $\mathrm{F}$. were frequent away from the natural habitat and near to housing and apiaries. Besides, Apis florea F., Andrena sp., Synoeca sp., wasps, Chalcid sp., Formica sp., Syrphus sp. and various Dipteran, Coleopteran, and Lepidopteran were also the flower visitors of buckwheat. The insects' diversity index was found higher near to natural habitat and lower away from the natural habitat. But, the 
evenness was observed to be higher near to natural habitat in comparison to away from the natural habitat.

Thus, the number and diversity of insect flower visitors of buckwheat increases on proximity to natural habitat suggesting buckwheat production near to natural habitat.

\section{References}

ABPSD (2013/014) Statistical information on Nepalese agriculture. Government of Nepal, Ministry of Agricultural Development. Agri-business Promotion and Statistics Division, Singha Durbar, Kathmandu, Nepal. $151 \mathrm{p}$.

Ahrne K, Bengtsson J and Elmqvist T (2009) Bumble bees (Bombus spp) along a gradient of increasing urbanization. PLoS One 4(5): e5574. DOI: 10.1371/journal.pone.0005574

Bjorkman T (1995) The role of honeybees (Hymenoptera: Apidae) in the pollination of buckwheat in eastern North America. Journal of Economic Entomology 88: 1739-1745. DOI: 10.1093/jee/88.6.1739

Chacoff NP and Aizen MA (2006) Edge effects on flower-visiting insects in grapefruit plantations bordering premontane subtropical forest. Journal of Applied Ecology 43 (1): 1827. DOI: $10.1111 / j .1365-2664.2005 .01116 . x$

Dhakal G (2003) Efficiency of Apis mellifera L. and Apis cerana F. for pollinating mustard and buckwheat. M. Sc. Thesis submitted to Institute of Agriculture and Animal Sciences, Rampur, Chitwan, Nepal. 59p.

Goodman R, Hepworth G, Kaczynski P, Mckee B, Clarke S and Bluett C (2001) Honeybee pollination of buckwheat (Fagopyrum esculentum Moench) cv. Manor. Australian Journal of Experimental Agriculture 41: 1217-1221. DOI: 10.1071/EA99008

Grigorenko V (1979) Okratnosti posešèenija pèelami greèichi. Pèelovodstvo 10:18-19.

Hoehn P (2008) Functional group diversity of bee pollinators increases crop yield. Proceedings of the Royal Society London. B: Biological Sciences 275: 2283-2291. DOI: 10.1098/rspb.2008.0405

Kearns CA, Inouye DW and Waser DW (1998) Endangered mutualisms: The conservation of plant-pollinator interactions. Annual Review of Ecology and Systematics 29: 83-112. DOI: 10.1146/annurev.ecolsys.29.1.83

Kremen C, Williams NM and Thorp RW (2002) Crop pollination from native bees at risk from agricultural intensification. Proceedings of the National Academy of Sciences USA 99(26): 16812-16816. DOI: 10.1073/pnas.262413599

Marshall HG and Pomeranz Y (1982) Buckwheat: description, breeding, production and utilization. In: Y. Pomeranz (ed.) Advances in Cereal Science and Technology (5), American Association of Cereal Chemist. Incorporated Inc., St. Paul, Minnesota, USA. pp. 157-210.

McGregor SE (1976) Insect pollination of cultivated crop plants. U. S. Department of Agriculture (USDA). Handbook Number 496, Governmental Printing Office, Washington DC, USA. $411 \mathrm{p}$.

Nolan KA and Callahan JE (2006) Beachcomber biology: The Shannon-Weiner Species Diversity Index. In: M.A. O'Donnell (eds.) Proceedings of the 27th Workshop/Conference of the Association for Biology Laboratory Education (ABLE) 27: 334-338.

NRC (2007) Status of pollinators in North America. In: M. Berenbaum, P. Bernhardt, S. Buchmann, N.W. Calderone, P. Goldstein, D. W. Inouye, P. G. Kevan, C. Kremen, R. A. Medellin, T. Ricketts, G. E. Robinson, A. A. Snow, S. M. Swinton, L. B. Thien and F. C. Thompson (eds.) The National Academics Press, Washington DC, USA.

Root RB (1973) Organization of plant-arthropod association in simple and diverse habitats: the fauna of collards (Brassica oleracea). Ecological Monographs 43(1): 95-124. DOI: $10.2307 / 1942161$

Westphal CR, Bommarco G, Carre E, Lamborn N, Morison T, Petanidou SG, Potts SP, Roberts M, Szentgyorgyi H, Tscheulin T, Vaissiere BE, Woyciechowski M, Biesmeijer JC, Kunin, Settele J and Steffan-Dewemter I (2008) Measuring bee diversity in different European habitats and biogeographical regions. Ecological Monographs 78: 653671. DOI: $10.1890 / 07-1292.1$

Zanette LRS, Martins RP and Ribeiro SP (2008) Effects of urbanization on Neotropical wasp and bee assemblages in a Brazilian metropolis. Landscape and Urban Planning 71: 105-121. DOI: 10.1016/j.landurbplan.2004.02.003 